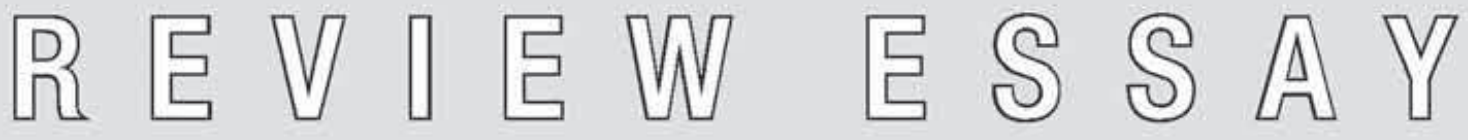

af Margareta Bertilsson

\title{
Om hockey-grafen, det goda livet och allmänningens tragedi: klimatfrågan i sociologisk belysning
}

Har sociologin något att bidra med till förståelsen och lösningen av klimatproblemet? Är vi som disciplin överkörda av de teknisk-naturvetenskapliga modellerna i vårt svärmande för den gamla tidens ordnings- och konfliktlösningar? Kan den sociala frågan återupplivas på det globala planet med orättvisor och orättfärdigheter av en så kollosal kaliber att perspektivet hisnar?

Efter att ha läst ett antal texter skrivna av framträdande sociologer som Ulrich Beck, Anthony Giddens, John Urry m.fl. blir man som läsare ganska hoppfull om att sociologi inte alls behöver befara sin egen undergång i klimatdebatten, snarare tvärtom! Men problemet är att de sociologiska perspektiven på klimatfrågan inte riktigt trängt igenom debatten, inte ens bland sociologer. $^{1}$

Eskalerande klimatkriser med översvämningar, orkaner, skogsbränder som nu inte längre går att kontrollera tekniskt-rationellt kan antingen utgöra slutet på livet som vi känner det - eller också utgöra början på något helt nytt (som vårt traditionella förståelsemönster ännu inte kan greppa). ${ }^{2}$ I redogörelsen nedan avhåller jag mig från de mest extrema ytterpunkterna om absolut förtvivlan eller dess motpol, ett eskatologiskt hopp om något nytt som vi inte känner. Likt den bundne Odysseus kryssar jag mellan Skylla och Karybdis, hopp och förtvivlan, i syfte att fånga en framkomlig farväg för sociologins vidkommande i en värld vars (o)ordningar vi inte känner. 


\section{Hockeyklubb-grafen och det goda livet - om medelklas- sens uppgång (och fall?)}

Med den industriella produktionen i slutet av 1800-talet tilltar CO2 utsläppen, till att börja med ganska långsamt men tillräckligt markant för att man ska kunna mäta en ökning i det mer naturliga flödet. ${ }^{3}$ Under mellankrigstiden med depressionen kan man t.o.m. notera en utsläppsminskning. Efter kriget, kring 1950 och därefter, ökade utsläppen med exponentiell kraft. Ökningen kan illustreras med hjälp av en graf som har formen av en hockeyklubba. Hockey-grafen illustrerar det som klimatforskarna kallar för den antropogena perioden: den människoskapta uppvärmningen (se också Blok i detta nr.) ${ }^{4}$

USA och Kina speciellt, men nu också en rad andra utvecklingsländer, har omättliga behov av energi för att upprätthålla sin produktion av varor och konsumtion av tjänster. Deras energi-behov mättas huvudsakligen av fossila bränslen som kol, olja och gas. När Mellanösterns regimer vacklar (som idag) och en stabil energitillförsel därifrån kan bli osäker i framtiden, måste energislukande marknader söka nya jaktmarker. I USA sker detta med alltmer aggressiv offshore borrning utanför Alaska i känsliga kustområden eller också i Mexikanska Golfen. Här sker som bekant förfärliga olyckor som BPskandalen för något år sedan. Naturparker är inte längre fredade områden. I gränstrakterna mellan USA och Kanada tvättas stora sandområden i jakten på olja och befolkningsgrupper tvingas flytta. Somalia och Sudan utgör nya sökområden. Grönland har på senare år utvecklats till ett verkligt hot spot för oljeintressenter från många kontinenter.

I Climate Change and Society (2011) utvecklar John Urry tesen om hur oljan kom att utgöra själva navet för det 20'e seklets väldiga expansion i Västvärlden och därmed blev till en ödesfråga för hela civilisationen, något som enligt honom hittills föga har uppmärksammats av sociologin. Oljans dubbla förbannelse ligger i att den till stor del har varit medverkande till den underutveckling som vi ser i Mellanöstern och som nu med den arabiska våren är i uppbrott: fastfrysning av medeltida makt/klan hierarkier där tyranner exproprierar enorma oljerikedomar att säljas på spotmarknader till Väst. Eftersom oljeresurserna var mer än tillräckliga i att bygga upp ofattlig rikedom, kom en modernisering aldrig igång i dessa regioner. Gamla kolonialstater styckade till synes med linjaler upp klan- beduinsamhällena och skapade därmed defekta stater, allt i syfte att tillförsäkra sig oljeresurser. Första världskrigets krigförande stater behövde ansenliga energiresurser (kol och olja) för att på järnväg transportera trupper och kanoner; och med andra världskrigets flyg, tanks och truppförflyttningar kom västvärldens beroende av olja att bli än mer cementerat. Folkmordet på armenier i Turkiet kan i själva verket också ses som ett indirekt resultat av oljans förbannelse: armenierna bebodde de områden i Turkiet som tyskarna i samarbete med turkarna önskade att expropriera, eftersom oljeledningar skulle dras här och tillförsäkra tyskarna en stabil tillförsel. ${ }^{5}$ Det första världskrigets behov och produktion av (auto) mobila 
enheter (tanks, tåg) lägger, i Urrys perspektiv, grundstoden till vårt senare oljeberoende. Det andra världskrigets energislukande avancerade farkoster på land, på hav och i luften cementerade ytterligare på vårt olje-beroende. Med Ulrich Becks terminologi blev riskerna också mera osynliga; krutlukten försvann ut i rymden och ned i havet. Det helt moderna kriget som nu i Irak, Afghanistan eller Libyen visar ytterligare på hur Västvärldens makter förbrukar hämningslösa olje- och energi-resurser; tänk bara på vad det kostar i energi att transportera landtrupper, hangarfartyg, tanks, jaktflyg och missiler över kontinenter.

Under mellankrigsåren, och speciellt efter 2 världskrigets slut, kom krigets insikter om energi att spilla över i mer fredliga former och kraftigt medverka till rikedomsalstring för vanligt folk: en VW, en Saab, eller rent av en Volvo fanns snart inom räckhåll för varje arbetande familj. Med charterresor till snart sagt jordens alla hörn utvecklades mobiliteten och energiförbruket enormt. Ingen tänkte över att den stegrade mobilitetsfrihet hade ett pris: utsläpp av CO2 expanderade i takt med vår frihet att resa vart vi önskade. Därtill kom masskonsumtionen av alla möjliga bekvämlighetsting: kylskåp, mikrovågsugn, elektriska tandborstar, rakapparater, kaffemaskiner, radio, TV, datorer i en ändlös spiral. Livet blev ganska bekvämt för oss här i västvärlden och för mindre enklaver i resten av världen. Medelklassen frodades, produktionshjulen var fullt i gång, och konsumtionen av varor och tjänster såg ingen ända. I sociologisk bemärkelse sammanfaller perioden med senmoderniteten och det goda livet som vi känner det i form av demokratisk expansion med minskning av Gini-koefficienter på båda sidor av Atlanten. Det skandinaviska välfärdssamhället är en produkt av att kolen, oljan och gasen (i Sverige och Finland också vatten- och atomkraft) fanns att tillgå i rikliga mängder: det är lättare att producera rättvisa när det finns gott om energi. Oljekrisen under 1970-talet uppvägdes av att man fann rikliga gas- och oljefält i Nordsjön.

\section{Allmänningens tragedi som medelklassens drama}

Hockey-grafen beskriver på sitt sätt också allmänningens tragedi. Så kallas det klassiska sociala dilemma som inte minst Karl Marx och tidigare Thomas Hobbes fruktbart bearbetat: när en fårägare i England upptäckte att han kunde öka antalet får på samma areal med ringa extra arbetsinsats, gjorde han en god vinst. Men när det stora flertalet följde hans exempel och ökade sitt boskapsinnehav, tilltog inte bara konkurrensen mellan fårägarna med fallande vinst och utslagning som konsekvens. Därtill kom att det ökade boskapsinnehavet också utsög jordens egen bärkraft, något som framtvingade större boskapshjordar och rationalisering av arbetet för att ägarna skulle kunna upprätthålla sin levnadsstandard. Den kollektiva konsekvensen blev att alla fick det sämre över tid; till slut räckte inte ens jordens resurser längre till. Fåravlarna drog omsider till Australien, där det som bekant råder perioder med olidlig torka idag, i vars spår okontrollerade skogsbränder snabbt sprids vida omkring. 
Hockeyklubbgrafen illustrerar det globala dilemma som följer i klimatförändringarnas spår. När några få förmögna amerikanare och europeiska aristokrater tuffade runt i sina T-Fords, tog miljön inte någon större skada och utsläppen var fortfarande negligerbara. När Adolf Hitler byggde den tyska Autobahn och stimulerade produktionen av folkbilarna, gjorde han det möjligt för en bredare medelklass att komma i åtnjutande av den rörelsefrihet som tidigare bara var förunnad en rik överklass. Utvecklingen av massbilism gav oss i övrigt stor komfort och fick samhällsekonomin att blomstra med utflyttning till förstaden, massproduktion av enfamiljshus och de därmed upp-komna följdbehoven att köpa kylskåp, tvätt- och diskmaskiner. Vi blev, med Urrys ord, "stigavhängiga" fossila bränslen, speciellt oljan. Bensindrivna bilar konkurrerade snabbt ut andra drivmedel som ånga, elektricitet och gas, helt enkelt för att det var ganska enkelt att transportera bensin via ledningar och tankbilar och fylla tanken vid behov. Det samma gäller de oljeuppvärmda husen med sina behållare som tankbilar med jämna mellanrum fyller på. Oljan betjänar ett väldigt nätverk av heterogena aktanter (Latour) runt om i våra regioner och den binder oss farligt samman också med de ökända regimerna i Mellanöstern.

Allmänningens tragedi visar sig inte minst $i$ alla de livets njutningsvaror som den breda allmänheten nu fått tillgång till. Gamla LP plattor producerades med hjälp av olja och skänkte en bred medelklass möjlighet till att via skivspelaren avnjuta Mozart eller Strauss, något som tidigare bara förunnades en exklusiv skara av klassiska musikälskare med tillgång till koncertlokaler. Musikälskare hävdar ännu idag att återgivningen av musik via Ipod inte på något sätt kan konkurrera med de gamla LP-plattorna med olja som beståndsdel.

Det goda livet skördar sina offer. Naturens resurser är ändliga, förr eller senare sinar oljekällorna och nya källor måste finnas. Alternativ till oljan? Hur är det möjligt att upparbeta CO2 neutrala energi källor? Hur ska man globalt lösa allmänningens tragedi? Kan sociologins klassiska lösningstekniker alls vara till någon hjälp?

\section{Maktens logik: Över- och underordning}

Sociologin växte sig stark i kampen om rikedomsfördelning i det förra århundradet. Motsättningen mellan kapital och arbete gav upphov till klasskonflikter och till den ideologiska spänningen mellan socialism och kapitalism. Den socialdemokratiska lösningen krävde sociologiska undersökningar om omfattningen av arbetarklassens misär och om konsekvenserna av diverse statliga ingrepp. Kvinnofrågan och sexualfrågan kunde också underläggas maktens över- och underordning. Invandrarfrågan har väl också sin inneboende sociologiska logik i över- och underordning mellan majoritets- och minoritetsbefolkning.

Fungerar maktlogiken också i den globalt omfattande klimatfrågan? Här blir den gällande maktlogiken mera komplicerad eftersom så många dispa- 
rata dimensioner är i spel. Om en central motsats lokaliseras till den mellan kultur och natur, så uppstår problemet med att lokalisera det sociala livets tillhörighet: det sociala ligger typiskt som både-och, som sammanvävd natur och kultur. Klimatfrågan skapar förvirring för hur ska sociologin greppa om väder och vind, om den arktiska uppvärmningen eller översvämningarna i Bangladesh? ${ }^{6}$

Visst skänker klimathotet rika möjligheter till kapitalism- och civilisationskritik: kapitalismen har hämningslöst utnyttjat naturen och dess resurser i en sådan omfattning att naturen som klimat nu slår tillbaka som "den undertryckte andre". Men det sociologiska problemet med att anlägga offer-perspektivet på den exploaterade naturen (som den andre) är att inget självklart subjekt föreligger. I sin senaste bok The Politics of Climate Change (2009) kritiserar Anthony Giddens den gröna rörelsen för att lägga beslag på naturen som något heligt och därmed försvåra möjliga lösningar på den allmänningens tragedi som nu hotar världsordningen! Naturens resurser och i förlängningen klimatet är ett "gemensamt godo"som enligt honom inte kan eller ska underläggas bestämda intressen. Sociologins traditionella maktlogik kräver att man kan identifiera bestämda och varaktiga relationer mellan härskare och offer, men i klimatfrågan råder det besvärliga läget att vi alla förr eller senare kan komma att bli offer för naturkrafter som ingen kan med säkerhet kontrollera.

Men kan man då bortse ifrån att klimatfrågan aktualiserar den gamla koloniala konflikten mellan "the West and the rest"? Ulrich Becks kosmopolitiska ansats grundas också på premissen att den sociala frågan nu är global: orättvisor och fördelningskamp gäller nu globen som helhet. ${ }^{7}$ I ett sådant perspektiv kan man fråga om inte klimatfrågan bara är en fortsättning på kolonialismen? Västvärldens hämningslösa utnyttjande av globens resurser och rovdrift på råvaror har lett fram till att klimatförändringar slår allra värst på de fattiga kontinenter som ingen eller liten delaktighet har i att klotets klimat försämrats.

Men vad händer om en sådan vision (att begränsa utsläpp med speciell adress till den rika världen) leder till det klassiska dilemmat att samtliga spelare förlorar? Det stora FN-mötet i Köpenhamn 2009 slutade som bekant i ett fiasko: men det var inte primärt den kapitalistiska utsugningen av jordens knappa resurser som olja, gas och kol som låg till grund för splittringen, men snarare frågan hur en utsläppsreduktion ska fördelas mellan rika och fattiga länder utan att hota global tillväxt. Komplexa rättvise- och fördelningsproblem omöjliggör enkla koordinationslösningar på den globala allmänningens tragedi som nu utgör ett hot mot oss alla. ${ }^{8}$ Det nyligen avslutade Durban-mötet slutade inte heller särskilt lyckligt med ett Kina och ett USA (de 2 största förorenarna) som nekar att underskriva internationella avtal.

Fördelningsproblematiken berör inte blott gapet mellan rika och fattiga kontinenter eller regioner här och nu, men har en ytterligare tidsdimension i det att kommande generationer också i den rika västvärlden riskerar att få en 
sämre levnadsstandard än sina föräldrar dels som en konsekvens av klimatförsämringar och dels som en konsekvens av att också den rika västvärlden måste pålägga medborgare inskränkningar avseende utsläpp. Förhållandet mellan "oss och dem" berör då inte bara samtidens rika och fattiga, men också fördelning mellan samtid och framtid: våra barn och barnbarn kan komma att vända sin förbannelse mot oss som rövade bort deras möjligheter till ett gott liv.

När fördelningsproblematiken är av en sådan omfattning och utsträckning i det globala tidsrummet är det svårt att precist bestämma vem som är offer och vem som är gärningsmän. Det är klart att man kan skuldbelägga kapitalismen, industri-samhället, moderniseringen och mass-konsumtion som varande själva drivkraften till ett blint utnyttjande av fossila bränslen och därmed till CO2 utsläpp som hockeyklubbgrafen visar. Men vilka är de långsiktiga perspektiven i en sådan skuldbörda vad gäller utvecklingsländernas legitima krav till rikedomsväxt och välstånd? Ska vi i det rika Väst predika för resten av världen att våra konsumtions- och levnadsvanor är roten till det onda? På så sätt riskerar vi att vidareföra kristendomens och kolonialiseringens tunga arv, nu i form av klimat-upplysning.

\section{Likgiltighetens paradox - klimathotets dolda sida}

De tyska socialpsykologerna Claus Leggewie och Harald Welzer ger i sin bok Slutet på Världen så som vi känner den (sv. översättning 2010) uttryck åt ett starkt bekymmer över stora befolkningsgruppers "kollektiva likgiltighet" vad gäller klimathotet. Anthony Giddens formulerar denna kollektiva likgiltighet som "Giddens paradox": så länge man inte själv inser en fara, finns den inte för oss; i den stund faran blir verklig, ja då är det för sent att alls handla. Människans benägenhet att inte inse faror i sin omgivning och lägga om handlingsmönster för att bättre klara av dessa faror kan förklara, menar Leggewie och Welzer, att de norska vikingarna dog ut som grupp och kultur på Grönland under senare delen av medeltiden: de envisades med att fortsätta med boskapsskötsel, även om klimatet då blev betydligt kallare. Om de istället hade tagit lärdom av inuiterna och gått över till att livnära sig på fisk och sälar, hade de kunnat överleva. Samma socialpsykologiska tes kan kasta ljus över Påsköns - och säkert flera indiansamhällens - undergång: man högg ner regnskogen för att använda trädstammar till att transportera väldiga stenar till högt liggande tempel, och därmed var man själv delaktig i civilisationens undergång. Med regnskogens försvinnande försvann också grundvalen för den egna existensen: det fanns inte längre något villebråd att jaga eller fånga. Vi moderna människor beter oss på samma idiotiska sätt, när vi envisas med att upprätthålla torskkvoter i Nordsjön (när torsken är utrotningshotad) eller fortsatt (kapitalistisk) djurhållning trots att utsläppen av metangas i atmosfären är med till att påverka drivhusgasen. Det yttersta hotet mot vår egen kultur kommer då inte utifrån stratosfären utan är snarare det långsiktiga icke-avsedda resultatet av vår egen dumhet. I evolutionsteoretiskt ljus kan ett 
sådant (struts)beteende förklara civilisationers uppgång och fall. I klimatfrågan leder det till att vi negligerar eller förnekar det vi inte förstår, något som på sikt är med till att förvärra de problem som vi står inför, ja kanske utgöra den sista spiken i kistan. Likgiltigheten hos stora befolkningsgrupper i klimatfrågan är då en del av själva faran, ja kanske den verkliga drivkraften i den allmänningens tragedi som nu hotar människosläktet.

\section{Framtidscenarier - och deras konsekvenser}

FNs klimatpanel opererar med ett antal scenarier i försöket att skriva fram möjliga konsekvenser. På samma sätt kan man med Urry och andra skriva fram scenarier och värdera deras konsekvenser för det sociala livets klimatologiska fortbestånd.

Förevigad konsumism är den moderna kapitalismens dominerande livs- och handlingsmönster. Denna livsform förefaller att med blixtens hastighet sprida sig till de nya kapitalistländerna runt om i världen, och det är i dessa delar av världen som den tynande västkapitalismen nu ser en framtid: om vi nu också kan sälja SAAB produktionen av bilar till kineserna såsom vi lyckades med Volvo, går det framåt med ekonomin. Men konsumismen är i perspektivet av allmänningens tragedi i längden inte hållbar: med ökade utsläpp av gaser och föroreningar, blir samhällslivet till slut ohållbart och imploderar.

Men konsumismen kan kanske disciplineras i en omfattning som gör den möjlig i ett långtidsperspektiv: konsumenter kan uppfostras till att utkräva (energi)kvalité av de varor som de inhandlar ungefär i den omfattning som vi ser i våra prima nordiska länder, men då som en ganska elitär livsform, starkt reglerad antingen av statssubventioner eller också upprätthållen av välmående medborgare. Allmänningens tragedi hotar dubbelt: antingen i tillkomsten av en exklusiv global elit och en fattig under- och medelklass vars existens hela tiden är hotad (som nu i USA). I evolutionärt hänseende är medelklassens livsform och därmed det demokratiska majoritetstyret starkt utrotningshotat.

Regional återhållsamhet (landsbygdens återkomst) är en möjlighet, men som i fallet ovan med ekonomistarka konsumenter är också detta scenario att se som begränsat till de redan frälsta. Torvehallarne på Israels Plads illustrerar hur vi på nytt med glädje konsumerar det som är lokalt producerat. En regional återhållsamhet kan helt klart slå igenom i vissa befolkningsskikt, men att det skulle vara en storskalig lösning på klimatproblemen i en global värld är nog osannolikt. Jordens grödor är inte rättvist fördelade, och det skulle vara moraliskt förkastligt att förmena Afrika att exportera kaffe och ris till oss i Väst.

Regionala krigshärdar under ledning av bandithövdingar är det värsta scenario som vi kan föreställa oss. Utvecklingen i Afghanistan, Pakistan, Somalia och nog också i Irak skrämmer. Med den arabiska våren i Mellanöstern hade vi förhoppningar om att demokrati till sist ville växa fram som folkrörelser, när tyranner störtas. Men utvecklingen kan lika gärna gå i den riktning att lokala 
hövdingar av en eller annan trosåskådning lägger beslag på de rika resurser som finns och bekämpar varandra eller också utsätter gamla härskarländer för utpressning som nu i Somalia. Vi kan redan skönja konturerna av hur vi här i Nordeuropa kan förlora suveränitet som en konsekvens av att vår energitillförsel till stor del säkras av den ryska gasledningen Gasprom i Östersjön. Putin och hans gelikar är inte just behagliga sängkamrater.

Lågenergi samhällen, smart teknologi, utnyttjande av digitala nätverk: I detta hoppfulla scenario ligger Urrys (och många andras) dröm om en värdig framtid för oss alla, inte bara väst. Det är möjligt att vi med intelligent teknologi kan lära att omsätta våra avfallsprodukter till energi och på så sätt bli självproducerande; åtminstone är detta drömmen om en framtid där vi lärt oss av tidigare misstag. Om vi kan kopplas upp med hjälp av nätet och ha Skypesamvaro, befrias vi från alla de vanvettiga flygresor där vi ska ta av oss bälte och skor i kontrollen och bli skamlöst genomlysta för eventuella vapen. I detta scenario utmanas sociologins klockartro på ansiktsrelationer: är det nödvändigt att vara fysiskt tillsammans för att erfara känslomässiga stämningar? Kan vi känna empati på avstånd?

Giddens har en stark tilltro till smart planering och teknologi, men till skillnad från Urry utvecklar han ganska hoppfulla tankar om hur en framtida klimatpolitik inte bara kan återupprätta den yttre natur som vi är på väg att förstöra, men också styrka statens "intervenerande och koordinerande" roll i att utnyttja marknadskrafternas dynamik. Han myntar i sammanhanget ett nytt statsbegrepp, the ensuring state. Den tredje vägen och den europeiska socialdemokratins visioner har med klimatpolitik fått ny näring här.

Det som överraskar läsaren är Giddens kritik mot den gröna rörelsen och dess fundamentalism $i$ tron på en immanent natur att bevaras och helst återställas som den nu var en gång. Naturens värde ligger i de relationer som vi människor har visavis denna natur. En konsekvens av denna hållning är att Giddens nu också ställer sig kritisk till "försiktighetsprincipen" som ju länge har markerat en slags demarkationslinje mellan EU och USA/resten av världen. ${ }^{9}$ Giddens' kritik av den europeiska försiktighetprincipen går ut på att den 1) förskotterar ett kausalt förlopp som 2) leder till en obenägenhet att ta risker. Istället förespråkar han en aktiv risk-politik som innebär att balansera fördelar med nackdelar med att ingripa/respektive inte att ingripa (t.ex. med $\mathrm{GMO}$ ). Han är också en varm förespråkare för att dela upp klimat-bördan som t.ex. emission av $\mathrm{CO} 2$ mellan redan utvecklade och utvecklingsländer: de senare som Kina och Indien måste tillåtas större utsläpp för att komma fatt i nivå med utvecklade länder för att därefter fasa ut utsläpp. USA och Europa måste däremot starkt begränsa sina utsläpp genom ev. handel av kvoter med utvecklingsländer samtidigt med att experimentera med klimat-vänlig politik på alla områden. Om Urry sätter sin tilltro till ett teknologiskt fix som möjlig koordinationslösning på allmänningens tragedi förespråkar Giddens ett politiskt sådant. En "smart" stat kan återta initiativet och fullt ut utnyttja 
marknadens och vetenskapens resurser. Giddens har nu antagit en roll som postpolitisk teknokrat med ambitioner att rådgiva statsledare: Bill Clinton har skrivit hans baksidestext.

\section{Allmänningens tragedi - och sociologins återkomst?}

Urrys sociologiska komplexitetstes med stigavhängighet och "tippunkter" har i övrigt starka gemensamhetspunkter med modern naturvetenskap sådan som vi ser den i paleontologi, geologi och astrofysik. Istället för stabilitet och regelbundenhet ligger det i dessa vetenskapers synsätt att räkna med språng, oregelbundenhet och "svarta hål". Perioder av relativ stabilitet kan komma att avlösas av perioder av instabilitet, när allt vad som tidigare byggts upp gradvis störtar samman och imploderar. Sådana händelser har väldiga konsekvenser, men vetenskapen var (och är) maktlös i att förutsäga skeendet. Ingen kunde på förhand förutsäga den franska revolutionen eller för den skull murens fall i Europa för ca 20 år sedan. Det samma gäller den arabiska våren som vi nu ser också har kommit till Syrien. Ingen kunde på förhand förutsäga dessa händelser som när de väl kommer igång, så går det snabbt. Klimatfrågan illustrerar detta förlopp på exemplariskt vis, något som sociologin som vetenskap borde kunna exploatera: sociala skeenden tar allt som oftast samma abrupta former som de vi nu ser i naturens och klimatets många (o)ordningar.

Så vad kan vi sociologer lära av klimatfrågan? Visst förekommer det oordning i naturen (som i samhället), och i oordningen kan vi lära oss om den ordning (stigavhängighet) som trots allt sätter ramar för de val vi har som individer och som system. ${ }^{10}$ Klimatfrågan, jordens uppvärmning och tilltagande katastrofer, lär oss något om materialitet, emergens och rörelse: att vår livsform avhänger stora energimängder som ska avhämtas någonstans ifrån; att energi är en ändlig resurs och att det vi hämtar från moder Jord ska återställas på ett eller annat sätt så att en ekologisk balans kan uppnås. Vad vi vidare kan lära av klimatkrisen är att senmoderniteten har ett pris, att en samhällsform som vilar på demokrati och med medelklassen som samhällets nav är en fragil historisk livsform som kräver omtanke och reflektion, inte bara för oss själva och de kommande nästa men också för alla de andra (som ingen skuld har i CO2 utsläpp men som betalar för vår extravagans) och som på sikt önskar att uppnå det goda liv som vi upp till nu har kunnat inhägna som vårt eget. Först i perspektivet av de utestängda andra inser vi omöjligheten i vårt sätt att leva. Klimatfrågan kan då med Ulrich Becks framtidscenario bli början på ett nytt kosmopolitisk perspektiv där vi genuint erkänner vår samhörighet med alla andra både i samtiden och i framtiden tack vare den förbindelse som jorden och materien utgör.

Få andra vetenskaper har upparbetat en tradition med att greppa om sammanhanget mellan abstraktion och konkretion, mellan teori och empiri, mellan ordning och oordning, mellan natur och kultur. Sociologins återkomst nu som generell evolutionsteori (Urry) i handlingsteoretiskt pragmatiskt sikte 
(Beck och Giddens) kräver nya materiella kontaktpunkter. Det är möjligt att klimatforskning på sikt kan utvecklas till en av sociologins viktigaste bundsförvanter, både teoretiskt och metodologiskt. Själv finner jag detta perspektiv utomordentligt spännande.

\title{
Noter
}

1. Flera av texterna publicerades i anslutning till det stora klimatmötet i Köpenhamn 2009. Den finansiella krisen kom emellan och förpassade klimatfrågan längre ner på den politiska och finansiella dagordningen, och säkert också den sociologiska.

2. Erik Swyngedouw ger en god översikt av apokalyptiska tendenser i "Apocalypse Forever? Post-political Populism and the Spectre of Climate Change" i Theory, Culture E Society 2010, Vol. 27, (2-3):213-232.

3. Den svenske forskaren Svante Arrhenius (1859-1927) var den förste som matematiskt formulerade relationen mellan $\mathrm{CO} 2$ och jordens uppvärmning (greenhouse effect).

4. Hockey-grafen har kritiserats för att vara konstruerad för att ensidigt mäta just det den ska: den människoskapta uppvärmningen (Se i övrigt Brian Wynnes text "Strange Weather, Again, Climate Science as Political Art" i Theory, Culture \& Society 2010, Vol. 27 (2-3):289-305.

5. Denna observation är författarens egen (MB) efter ett besök i Holocaustmuseet i Jerevan. Här förekommer antydningar om att oljetransporten krävde "sina offer": de armeniska bosättningarna kunde passande slaktas eftersom de låg $i$ vägen för oljeledningar.

6. Se Sheila Jasanoff "A New Climate for Society" i Theory, Culture \& Society 2010, Vol. 27 (23):233-253.

7. Se Ulrich Beck "Climate for Change, or How to Create a Green Modernity?" i Theory, Culture $\mathcal{E}$ Society 2010, Vol. 27 (2-3):254-266.

8. Se Bradley C. Park and J. Timmons Roberts artikel "Climate Change, Social Theory and Justice" i Theory, Culture \& Society 2010, Vol. 27 (2-3):134-166.

9. Denna princip finns i flera svårighetsgrader, allt ifrån att aldrig förorsaka skada till en mer uttunnad version att gå försiktigt tillväga med nya teknologier. Sheila Jasanoff, den välkända STS-forskaren, har i flera sammanhang med vördnad skrivet om EUs "ödmjukhetsteknologier" i kontrast till amerikansk miljö-teknologi som oftast utskriver bevisbördan "när skadan redan har skett".

10. Se Melina Cooper "Turbulent Worlds, Financial Markets and Environmental Crisis" i Theory, Culture \& Society 2010, Vol. 27 (2-3):167-190.

\section{Litteratur}

Giddens, Anthony 2009: The Politics of Climate Change. Cambridge: Polity Press.

Leggewie, Claus \& Welzer, Harald 2010: Slutet på världen så som vi känner den. Göteborg: Daidalos. (Original 2009: Das Ende der Welt wie wir sie kannten. Klima, Zukunft und die Chansen der Demokratie. Frankfurt a.M.: Fleishers Verlag.)

Theory, Culture E Society 2010, Vol. 27 (2-3): Special Issue on Climate Change and Society. (Refererade texter i fornoter.)

Urry, John 2011: Climate Change \& Society. Cambridge: Polity Press.

\author{
Margareta Bertilsson \\ E-mail: mb@soc.ku.dk
}

